\begin{tabular}{c} 
Journal of Business School \\
2019, 2(1): $1-22$ \\
DOI: $10.29226 /$ TR1010.2019.51 \\
\hline Journal Homepage: https://www.journalbusiness.org
\end{tabular}

\title{
The Productivity of SMEs in Mexico and Their Effect on Innovation, Using the Survey on Information Technologies and Communications, 2013 (ENTIC)
}

\author{
José G. Vargas-Hernández, M.B.A.; Ph.D.
}

Centro Universitario de Ciencias Económico Administrativas. Universidad de

Guadalajara

Periférico Norte 799 Edif. G201-7, Núcleo universitario Los Belenes, Zapopan, Jalisco, 45100, México

Jvargas2006@gmail.com, jgvh0811@yahoo.com, josevargas@cucea.udg.mx

\section{Vania Y. López-Mayorga}

Centro Universitario de Ciencias Económico Administrativas. Universidad de

Guadalajara

División del Norte 1904, Zapopan Jalisco, México vanialoma1006@gmail.com

\begin{abstract}
Small and medium enterprises (SMEs) in Mexico represent one of the main entities of economic activity that supports the bulk of the Mexican population; using statistics as a fundamental tool for conducting studies in the economic, natural, health sciences, among others, allows us to have proactive foundations for decision making within companies by senior executives and in the field public by officials responsible for promoting the growth of the industry in our country. This research tries to represent, under a statistical scheme, the use and disposition of Information and Communication Technologies (ICTs) as a tool to increase average productivity levels within companies and under the Cobb production function. -Douglas determines the ICT impact.
\end{abstract}

Keywords: SMEs, Innovation, Productivity, ICTs.

\section{Introduction}

In Mexico, the economic effects of the economic crisis suffered in 2008, as a result of excessive spending by Americans due to low interest rates, triggering an imbalance in the mortgage sector, is identified as the main cause of this crisis. For the country, the effects were evidenced in the real economy when our exports and remittances from the United States contracted, together with the reduction of confidence in the Mexican economy by entities that promoted the increase in R \& D (Research and Development). From these consequences the economy seems to have consolidated its stagnation in different areas of the economic activity, such as: mining, 
electricity, construction, manufacturing, commerce, services, transportation and communications. These activities represent the sectors that mostly absorb the Economically Active Population (PEA: Population aged 15 and over) through small and medium enterprises (SMEs).

With regard to the income from oil exports for December 2015, these prices are down, due to pressure from the member countries of the Organization of Petroleum Exporting Countries (OPEC) to promote the supply of crude oil. If this trend continues for the fourth quarter of 2016, an oil surplus is expected (El Economista, 2015). All these factors that limit the dynamism of the Mexican economy cause the deepening of the weakening of economic activities, negatively impacting the activities carried out by SMEs in the quest to absorb as much of the EAP as possible.

One of the challenges for Mexican companies is to be at the forefront of current technological systems. Mexico as a developing economy is subject to the imitation of technologies from central countries such as the United States, Germany, Japan, France and the United Kingdom (G5). As Myro points out in 2010: in economies with a low level of development, [...], technical progress should be more based on imitation than on one's own technological effort, so that cases such as Mexico's policies on technological innovation should focus on imitation to achieve the technical progress sought by SMEs in our country.

This is how Mexico bases its innovative activity through reactive strategies that follow and imitate organizations. Pioneer nations such as Germany, Japan, the United States, among other developed nations, follow reactive strategies, since they are pioneers in technological innovations. Among the main results that Mexico has in terms of Science, Technology and Industry that was carried out by the Organization for Economic Cooperation and Development (OECD) in 2013, are summarized those:

A. Mexico suffers the consequences of a weak innovation environment, and investment in science and technology remains at a low level by OECD standards.

B. Among the main obstacles are: patterns of industrial specialization, high prevalence of micro-enterprises, skill gaps and an ICT infrastructure insufficiently developed and high cost.

C. Linkages between the research base and the underdeveloped economy, which translates into few scientific publications (OECD, 2013).

These characteristics, which currently prevail in conjunction with the low quality of educational services, make it difficult to build a solid technological base in the much sought-after technical progress, even though imitation. In this same report, it is mentioned that Mexico also faces a series of challenges due to the weaknesses of its ICT infrastructure, which include low penetration of broadband (both fixed and wireless), low average speeds of broadband connection and high prices (OECD, 2013).

Information and Communication Technologies (ICTs) play in business logistics a fundamental role in the praxis of economic subjects. Because of the importance that these tools have among the relations of the global economies, keeping them up to date is fundamental for the Mexican capitalist system.

The following pages of the document describe the general aspects of the methodology used, the statistical design in which the basic statistics are calculated, at first about the stratification carried out by INEGI, followed by the segmentation proposed in this research. At the end of the 
methodology section establishes the relevance of using the average productivity and the CobbDouglas production model.

In the results section, the general statistics for the stratification of INEGI and the proposal formed by small, large and medium-sized companies are presented, the description of the type of activity they perform, the distribution of their income, the items to the that allocate their investment. This section also describes the use of traditional communication media, as well as the impacts of ICTs. In this same section we present the impacts of ICTs such as email, the Internet, social networks and the website in aspects of competitiveness. The results of the two regression models are also presented. Finally, in the last section, the conclusions and a series of recommendations are presented.

\section{Background of the problem}

In the reconfiguration of productive paradigms, SMEs use sciences and techniques for the reconstruction of new technologies. Technology is understood as the sum of knowledge about the means and methods of production of goods and services (Luter, 1998), this same technology plays an important role in economic theory.

To define innovation, it is necessary to differentiate between invention and innovation (Galindo, 2012 pp.53). Invention as the idea of a person about a product or process and innovation as the first attempt to put it into practice. Galindo (2012) also considers that for an invention to become an innovation, the company must combine different elements, such as: knowledge, skills, abilities and resources.

In neoclassical economic theory, innovations are understood as exogenous phenomena in the equation that seeks the equilibrium between supply and demand while the current of the positive school that interprets the economy as a dynamic system considers innovation as a variable endogenous (Hernández, 2009). The positive theory makes reference that although the human being could not create the matter, if it can create his utility, to increase it or to diminish it, in this it consists precisely the innovation. With this, it assumes the importance of the reasoning of the human being, the capacity to invent and to create new forms from subjects.

Schumpeter being one of the modern authors, distinguishes the innovations themselves and technical innovations in the studies on growth and economic development. Hernández, (2009) distinguishes these two types of innovations, the first referring to the systemic search for general explanations of a phenomenon and technical innovation as an original solution resulting from the synthesis of information about needs or desires, and information about the technical means by which they can be satisfied (Utterback, 1971, p.77 in Hernández, 2009). This appreciation previously noted, where the human being seeks welfare through the least effort, the invention of the wheel, the steam engine and the innumerable instruments we use in our lives reflect the technical progress we have made to meet " $n$ " human needs. Innovation is therefore an economic phenomenon that serves to create wealth and satisfy needs.

In this context, Hernández (2009) states that the variables that explain innovation are: entrepreneurial profits or the reduction of production costs, intentional research and development efforts, accumulation of human capital, exploitation of new inventions or in the application of mature technologies or new uses. For the company innovation is an important factor from any point in which it is considered, since it frees the market pressure in the creation or improvement of new products. Many companies that integrate markets base their innovations on scientific knowledge and technological developments measuring the innovation in number of patents for a certain period. 
Hernández, 2009 indicates that independent variables have to do with intensity or investment in research and development (Mansfield, 1963, Koeller, 1995, Gatti, 1998); with the provision of human capital according to the proportion of scientists and engineers in relation to company personnel, as well as the number of workers with the ability to execute changes or learn new skills (Koeller, 1995, Gatti, 1998, Afuah, 2002).

Companies being the primary entities of economic activities, innovation is a competitive advantage that allows them to extend their life in the market. Innovation and technological change serve each other so that the company that produces them obtains better returns. Cantú, 2006 classifies the innovations according to the magnitude of the change they imply, mentioning the following typology (Cantú, 2006 in Dussage, Hart and Ramanantsoa, 1992, p.1415):

A. Incremental: the articulation between concepts and components or architecture of the product is not changed, only some of its components or concepts are reinforced or improved.

B. Radical: both the architecture and the components are altered, in fact it is a new product.

C. Modular: the modular components of a product are radically changed but its architecture remains unchanged; the change from analogue to digital telephones is an example of this type of technological innovation.

D. Architectural: modifies the way in which the components and concepts of the product are articulated but the components and concepts only reinforce or remain without change, examples of these changes occur in personal computers and are not easily identifiable by consumers because they are at the system level.

In this way, innovations are transformations made by the human being of the goods provided by nature with the purpose of facilitating the activities carried out and obtaining some benefits when exchanging them with other individuals, not limited to exclusively technological concepts, but rather to find also innovations in the economic, social, organizational, strategic areas of the companies.

The PyMES are the economic units by excellence that train the individuals, that when realizing a physical activity exchange this effort for an economic remuneration, this in order to solve their physical needs and those of their dependents. Since small and medium-sized companies are responsible for absorbing this population stratum, it is necessary to analyze the use of ICTs as an alternative to growth. That is why one of the main problems faced by SMEs is the lag in technological equipment that causes competitive asymmetries and disadvantages compared to foreign companies established in our country.

The process of equipping companies in their different dimensions when settling in defined geographical areas causes economic growth in the region. The study of this process is necessary to determine the effects it has on human capital, both in the average productivity, and the effect of ICTs on production levels in the company.

This investigation seeks to analyze this process and the influence on the living conditions of the country. Companies in the country represent a great source of employment that encourage economic growth and social welfare. Thus, statistics supports the operational alternatives in the decision making of the company in order to promote growth and with it the living conditions of workers. 


\section{Review of the empirical literature}

To solve the changes that our global environment demands of different societies is through knowledge, the different economic, political and social facts rethink the solution of problems through new and sustainable techniques. The promotion and development that governments make regarding managing knowledge is directly linked to the work of enterprises, to increase profitability, generate regional growth, improve living conditions and other promoting environmental care.

In this quest for knowledge management, companies create new and better products, improve their production systems, utopian looking solving major social and economic problems such as health, education, poverty, quality of life, etc., claiming that these new improvements do not compromise environmental conditions. In this way, companies, universities and the government are responsible for responding with solutions, using different strategies, mechanisms and policies that contribute to the improvement of current conditions. The conception of economy, the knowledge that is currently developed and involved in the tasks of companies to achieve higher returns, has to do with analyzing the situation, setting the objectives and finally optimizing knowledge.

Among the main features of this global knowledge economy, as stated by ECLAC, in its report "Innovating to grow", it must be:

A. Greater codification of knowledge.

B. A Closer relationship between technology and science, with higher innovation rates and shorter product life cycles.

C. A Growing importance of innovation in GDP growth, as well as education and continuous learning.

D. Greater investment in intangible elements (research and development, education, software, among others) than in fixed capital, and

E. Substantial changes in the demand for qualifications in the labor market (Figueroa, 2015)

These characteristics that foster the emergence of technological innovations imply a process to reach a final product or technological improvement. The process to follow can be clearly understood through the following funnel, (Figueroa, 2015).

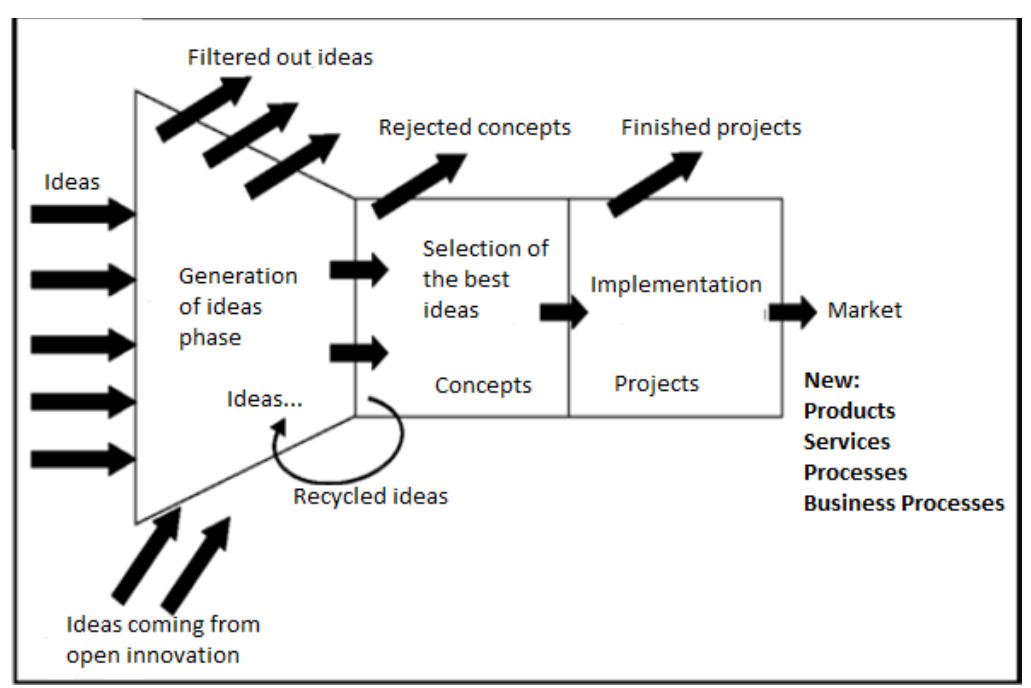

Figure 1. Funnel of innovation.

Source: Oxford English Dictionary, 2010 (Figueroa, 2015) 
In this funnel, all ideas are filtered by ideas that are feasibly applied and that respond to a market need, so its implementation results in new products, services, processes and business processes. The importance of working under this scheme is reflected in the decrease in costs of the companies. Finally, to ensure the success of any technological innovation as Figueroa (2015) mentions, a social need, social resources and a receptive social concept have to be combined.

\section{Research method}

\section{A. General aspects}

The use of Information and Communication Technologies (ICTs) by companies in our country has seen considerable growth in recent years. The use of computers, landlines, mobile phones, internet, among other technological resources, has become essential for the operation of any company.

The following pages analyze the situation for 2013 of the use of ICTs by companies with a staff of more than 10 people. These companies are carrying out activities such as: mining, electricity, construction, manufacturing, commerce, services, transportation and communications, according to the classification made by the North American Industrial Classification System 2007 (SCIAN2007). This analysis is done taking the Survey on Information Technologies and Communications 2013 (ENTIC, 2013) conducted by the National Institute of Statistics and Geography (INEGI).

The survey was designed under a probabilistic scheme so that the results obtained can be generalized for the total population. The population of companies that integrate with 10 workers and more gives a total of 157, 611 and the total sample selected is 6, 941 companies. The available results are those presented for 42 companies.

It is worth mentioning that in this descriptive research, it had a limited sample of the results of the ENTIC, 2013 published by INEGI within its website, which is a mere approximation as an exercise that it intends to do as a research work at the international level. mastery with the complete survey. This is a cross-sectional study since the survey deals with the use of ICTs in 2013.

\section{B. Statistical design}

The design used to carry out this research was an observational study, in which the ENTIC, 2013 is taken with the 42 companies that make up the database published by INEGI on its website. When carrying out this research it was decided to take all the companies as it was a limited database, so the results represent an exercise for the calculation of the final results that is proposed as thesis for the master's level.

The new stratification was carried out according to the size of the number of employees working in the company, so 3 groups were consolidated consisting of small companies that have a number of workers ranging from 1 to 50 employees, the medians of 51 to 250 employees and large companies that have more than 250 people employed.

\section{Statistical analysis}

In the statistical analysis are the basic statistics of the original stratification presented by the INEGI according to the employed personnel, which includes data on the investment in fixed assets of the companies that allow identifying the items with greater influence on average productivity, the availability of the media in which the behavior of companies is identified with the media to position their products and services. These same basic statistics were also determined for the impacts of the use of ICTs in the productivity of companies. This as an 
alternative to promote competitive advantages over larger national companies as well as foreign companies established in the country that represent a potential competition.

In the proposal that is made to restructure the sample in 3 new groups, the structure of their income, the disposition of the means of communication, the use of computer equipment and the impact of ICTs, are finally proposed. 2 regression models to determine the average productivity and a modification to the production model using the Cobb-Douglas model using the Minitab statistical program.

\section{Analysis of results}

INEGI performs a stratification according to the employed or employed personnel, classifying the companies based on this criterion.

Table 1. Classification of companies.

\begin{tabular}{|l|l|}
\hline Estrata of personnel employed & Sample of companies \\
\hline Total & 42 \\
\hline More than 751 & 10 \\
\hline 251 a 750 & 6 \\
\hline 51 a 250 & 14 \\
\hline 21 a 50 & 5 \\
\hline 10 a 20 & 5 \\
\hline 1 a 9 & 2 \\
\hline
\end{tabular}

The results presented by INEGI, stratum 3 absorbs $33 \%$ of companies, followed by Stratum 1 with $24 \%$, this stratum being large companies in terms of personnel, with more than 751 employed persons. The turn of the activities carried out by these companies are: television monitors, electric power commercialization, clothing retail trade, personnel transport service, crude oil, to name a few, this explains in some way the amount of personnel they require to develop their activities.

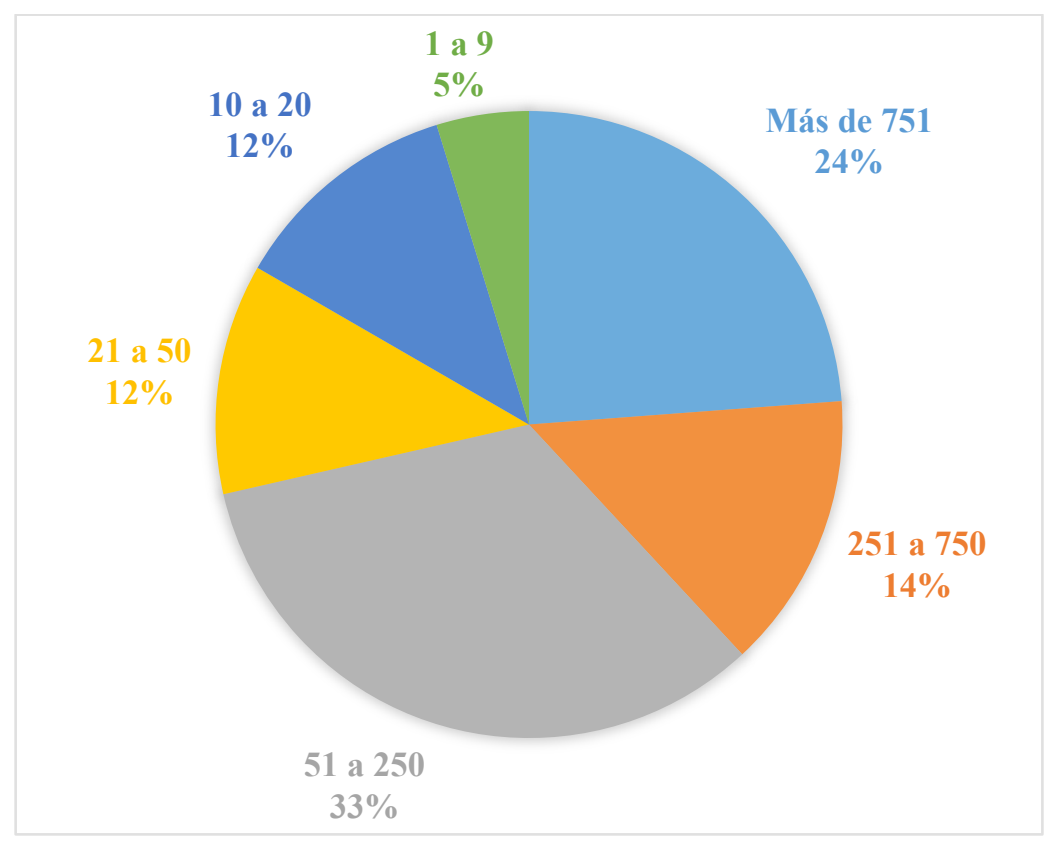

Figure 2. Distribution of the strata by employed personnel. Source: Own elaboration with data from the ENTIC, 2013. 
The business of the companies is presented in table 2. this classification is carried out by the OECD, with a total of 23 branches. The shift that predominates in the results presented by INEGI are the wholesale and retail sales and the complements of the service.

Table 2. Distribution of the companies by branch of activity.

\begin{tabular}{|c|c|c|}
\hline $\begin{array}{l}\text { Branch } \\
\text { of } \\
\text { activity } \\
\text { OCDE }\end{array}$ & Description OCDE & Companies \\
\hline 2 & Mining & 2 \\
\hline 8 & Textile & 1 \\
\hline 9 & Clothing and leather & 1 \\
\hline 13 & Pulp, paper and paper products & 1 \\
\hline 14 & Publications, printers and reproduction of recording media & 1 \\
\hline 19 & Chemical (pharmaceutical) & 1 \\
\hline 20 & Rubber and plastic products & 1 \\
\hline 23 & Ferrous basic metals & 1 \\
\hline 25 & Products made of metal & 2 \\
\hline 28 & Office, accounting and computer machinery & 1 \\
\hline 32 & $\mathrm{TV}$, radio and communications equipment & 1 \\
\hline 34 & Motor vehicles & 1 \\
\hline 37 & Aircraft & 1 \\
\hline 40 & Furniture & 1 \\
\hline 41 & Other manufactures not specified elsewhere & 1 \\
\hline 43 & Electricity & 1 \\
\hline 46 & Wholesales & 5 \\
\hline 48 & Transportation and storage & 3 \\
\hline 53 & Real estate, income and business activities & 1 \\
\hline 59 & Community, social and personal services & 3 \\
\hline SER & Complement services & 4 \\
\hline $46 \mathrm{~b}$ & Retail sales & 7 \\
\hline MEC & MEC Complement mining - construction & 1 \\
\hline Total & & 42 \\
\hline
\end{tabular}

\section{A. Investment and equity participation of companies}

Throughout economic history, talk about investment involves the injection of current assets to promote and reactivate some economic activity in order to grow this type of asset through yields. Within companies and any organization investments are made through direct injections of capital, for example the payment of wages and salaries, purchases of different inputs to make labor productive as the same production process, ICT equipment, among others. In the case of the study companies, it can be observed the distribution that is made of this investment being the items in machinery and equipment and the investment in computer equipment and peripherals that concentrate the largest amount of capital invested. 


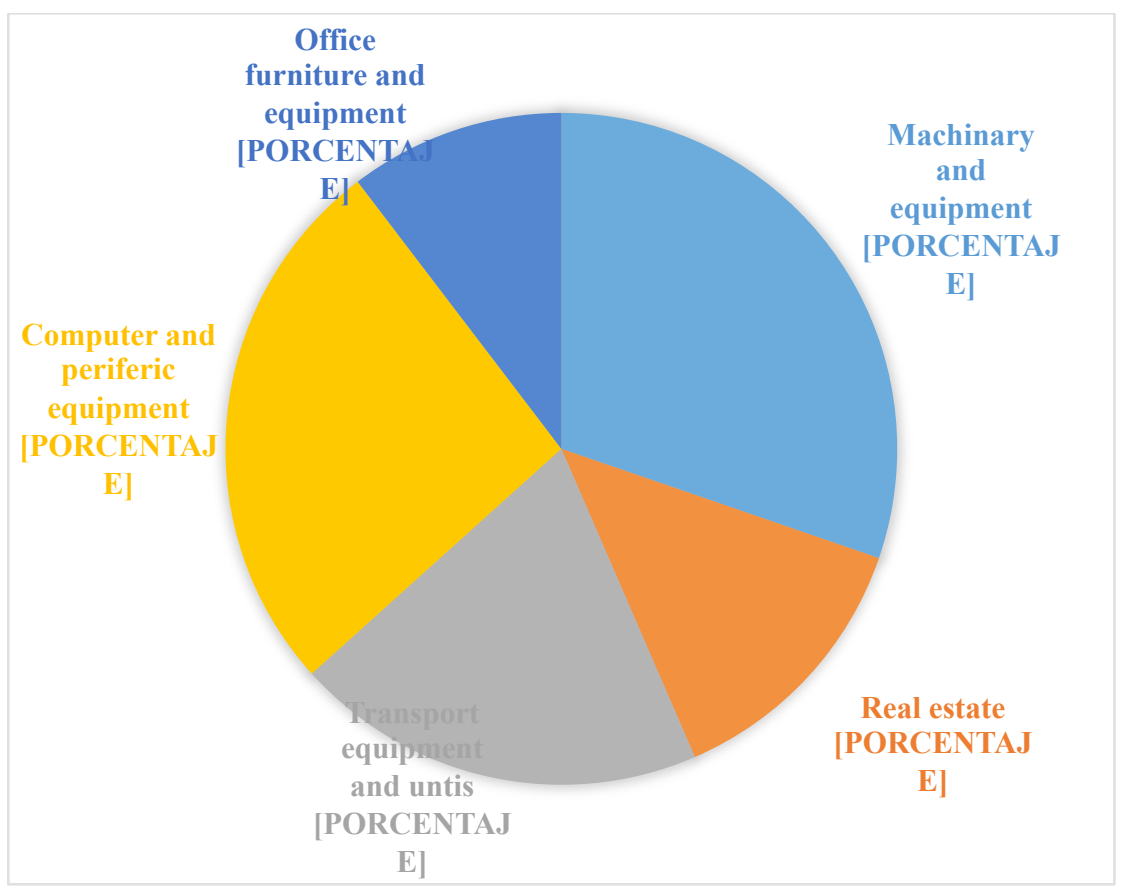

Figure 3. Investment in fixed assets of companies.

Source: Own elaboration with data from the ENTIC, 2013.

The information presented about the amounts of investment in fixed assets that companies make results with a large variance. In this way, through ranges it can be have a clearer vision. It can be seen that $54.76 \%$ of companies invest less than $\$ 999.00$ pesos. This investment ratio is a function of the size of the companies that for this research has been stratified in terms of the staff they have occupied.

Table 3. Investment amounts of companies

\begin{tabular}{|l|l|l|l|}
\hline Rank & Investment & Total companies & $\%$ of in vestment rank \\
\hline 1 & De \$0 a 99 & 13 & 30.95 \\
\hline 2 & De \$100 a 999 & 10 & 23.81 \\
\hline 3 & De \$1,000 a 9,999 & 10 & 23.81 \\
\hline 4 & De \$10,000 a 99,999 & 5 & 11.90 \\
\hline 5 & More than \$100,000 & 4 & 9.52 \\
\hline Total & & 42 & 100.00 \\
\hline
\end{tabular}

Source: Own elaboration

Continuing with the formation of the participation of the social capital of these companies, of the $42,78.57 \%$ is $100 \%$ national capital, then we have $19.05 \%$ with participation of foreign capital and a public company. Within companies with foreign capital participation (8 companies), 3 have $99 \%$ of foreign capital and 2 companies have $100 \%$ of this same type of capital.

\section{B. ICTs in companies: Investment, uses and impact}

The technological advances that society is currently suffering correspond to the satisfaction of the new needs that this has. Within the market composed of large, medium and small 
companies, the relationships between them have become closer. They link such simple matters as the purchase and sale of articles of daily commercial use, to the movement of large capitals that would, in short, impact the living conditions of the residents of any place or country where these movements occur.

In this way the use of ICTs is a tool within companies to make large and small movements of capital, to perform the administrative and operational tasks of the company, understood here the operability from inputs - outputs of goods until its commercialization and arrival to the final consumer.

The situation that predominates in the companies analyzed through the following graph, show that the companies which responded through a dichotomous variable (yes, no) about the resources with which they had at their disposal in the year immediately prior to the publication of the survey, the results are presented below:

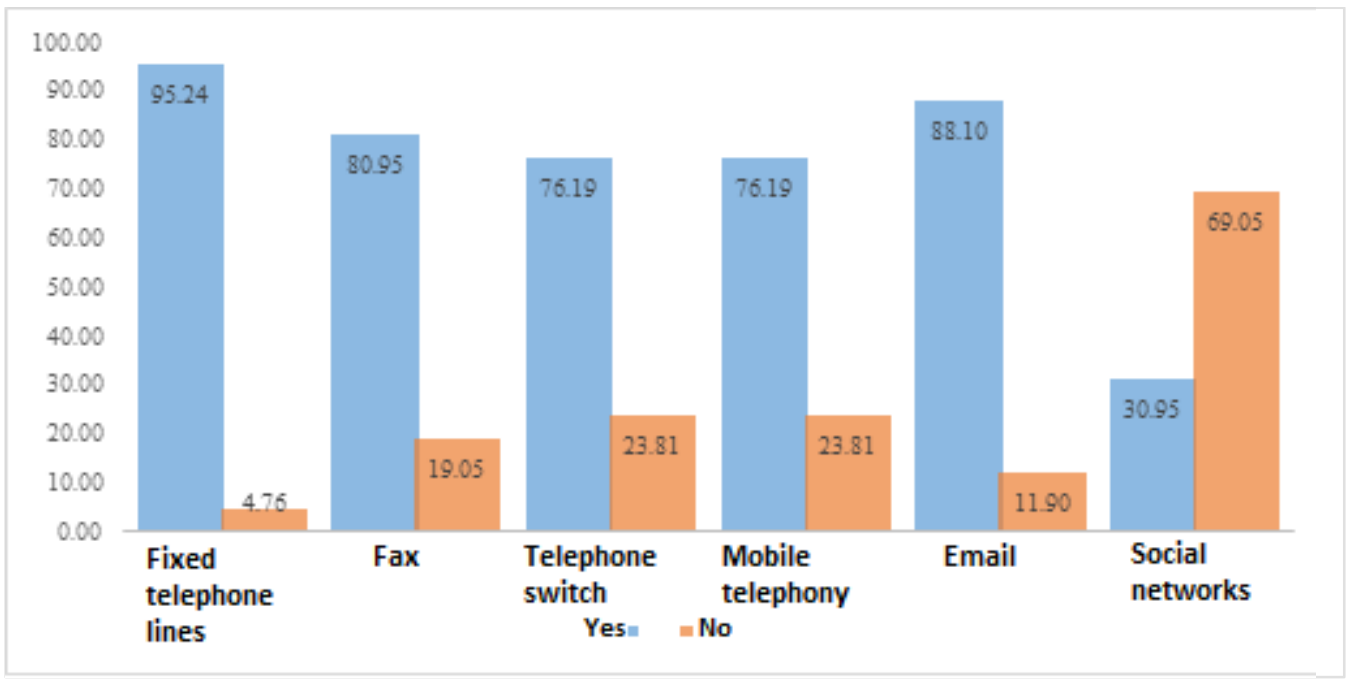

Figure 4. Availability of means of communication used by companies.

Source: Own elaboration with data from the ENTIC, 2013.

The provision of means of communication such as telephone lines, fax, switch, mobile, email and social networks by companies involves multiple internal and external tasks. The companies, as shown in figure 4, represent the use of the traditional means of communication par excellence, such as fixed telephones, a strong percentage, 80.95 and $76.19 \%$ in fax and commutator, respectively. The provision of mobile telephony is on par with the same percentage of a traditional means of communication such as fax $(76.19 \%)$. The email with $88.10 \%$ of the companies, proves to be only below the traditional landline phone the importance that has for the companies to have this ICT tool in the operation of their activities. On the other hand, it is seen that only $30.95 \%$ of these companies have social networks. Denote here the importance of the rise of social networks in recent years as they currently represent a niche of opportunity for the positioning and sales of companies.

The investments made by companies in the ICT category, are in the acquisition of computer equipment that includes: desktop computers (PC), mobile phones or laptops (laptop, notebook, netbook, tablet), workstations, servers, minicomputers, mainframes, supercomputers. In the results that INEGI presents, it is identified that on average each person employed within these companies has .35 computation equipment as media to perform the assigned activities. 
Within the use of these equipment $92.85 \%$ that declare percentages in stock, it is noted that $63.67 \%$ of that $92.85 \%$, is older than two years and only $17.62 \%$ of this equipment is less than one year. Taken into account the speed at which they depreciate (30\% each year) this represents for companies a signal to be updated with new products that allow them to increase their productivity.

Another important aspect to highlight in the use, management and acquisition of computer equipment by Mexican companies are the support that the Mexican government has to support productive economic activities of companies. One of these programs is the PROSOFT 3.0 that supports companies with low levels of development for the adoption and development of new ICTs. Even within their calls, the innovations of companies are encouraged, all with the objective of increasing productivity levels in the strategic sectors of the economy (SE, 2016).

For the results presented by the ENTIC (2013), 93\% of the companies did not receive any government support for these purposes. In the theoretical framework on the advances in the use of information technologies by companies, this use would imply significant advantages in the progress of the activities they carry out. When analyzing the situation of these 42 companies, it can be observed in the year of study, that the use of internet and email have impacts on the reduction of time of the processes of the companies.

The information collected by INEGI when applying its questionnaire on the impact of ICTs in the increase of sales and customers, reduction of time and costs, quality of services and market expansion is proposed based on the opinion of the person in charge of responding the survey, so it is a yes and no answer.

Although we do not count on the percentages of these increases or decreases to make specific estimates, this information helps to later consider the probabilities that these items have in decreasing or increasing productivity and production by making use of the internet, website, email or social networks. The most used instruments to increase sales were email and the Internet, which predominated in most of the categories: cost reduction, quality of services and customer growth.

Regarding the use of the website, it only impacts more or less significantly on the increase of customers. The issue of social networks turns out to be the one with less weight in these categories, having its greatest impact with $20.51 \%$ of companies that have social networks in the geographic expansion of their market.

In broad terms, these results represent the delay of companies in the use of ICTs to increase their productivity, since they are the tools we have in this century and mean the possibility of promoting competitiveness and growth in each of them. Stopping to observe the impact that the electronic mail is having within the operations of the companies in the period of surveying, it is noted that on average companies have .97 units of computer equipment to use with Internet access. Because the Internet network conditions the use of electronic mail, the people who used computer equipment with Internet access reach an average of 1.45 email accounts.

The average of email accounts combined with computer equipment with Internet access introduce, among other variables, the electronic commerce of goods and services offered by companies, which it will be analyzed later. In figure 5 we can observe these behaviors. 


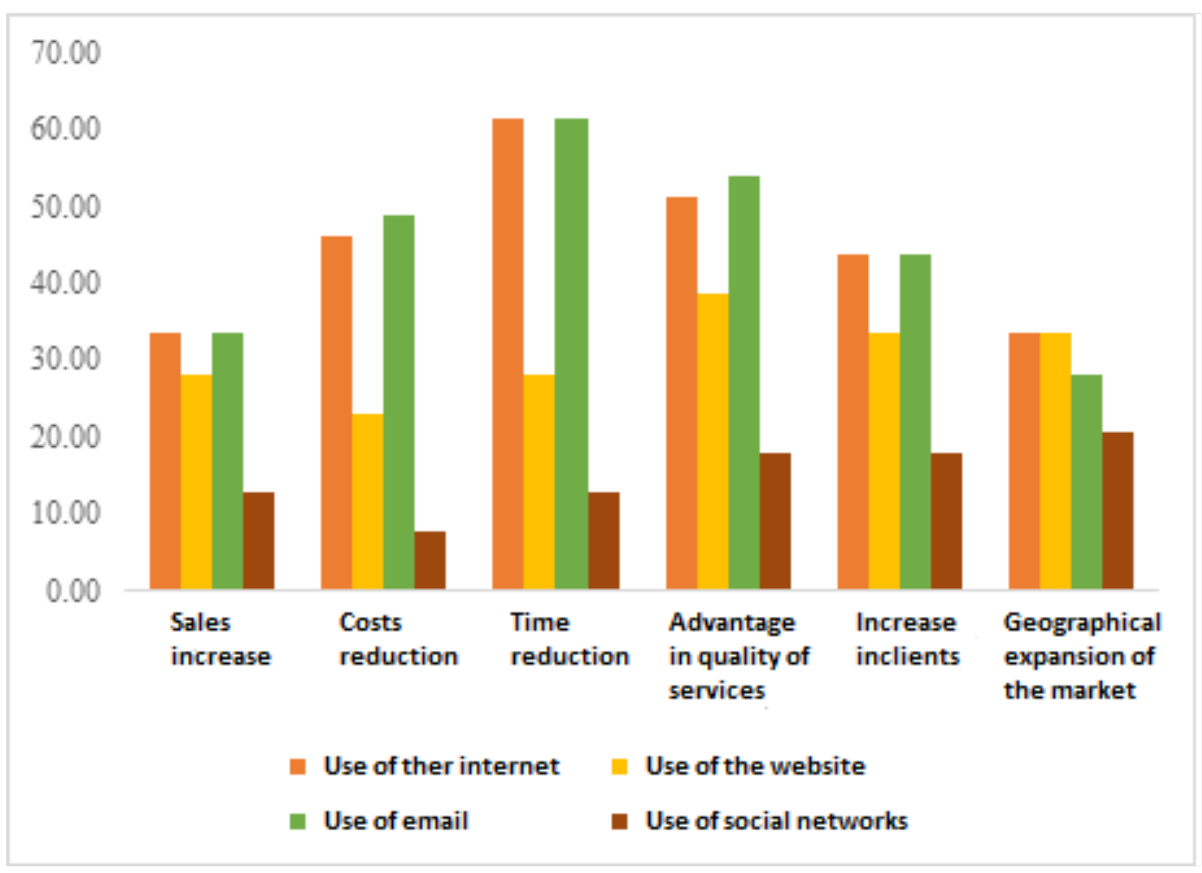

Figure 5. The impacts of ICTs on the competitiveness of companies.

Source: Own elaboration with data from the ENTIC, 2013

The increase due to the intensive use of ICTs would be a key factor together with the increase in productivity in the increase of yields, although as previously indicated, yields may increase due to the increase in prices, without this meaning an increase in the productivity of the company. These market forces are not very controllable by SMEs.

One aspect in which SMEs can have interference is in the training of their workers when using ICTs, since by keeping them trained they can update their knowledge of the factors that affect their market. Of the results presented by INEGI, only seven companies trained personnel taking between 2 to 100 courses in this period, a figure that shows information asymmetry due to the size of the company according to its personnel.

\section{The structure of the market of companies}

The outputs direction of companies made up of goods and services that they produce in the form of manufacturing, mining, energy and services in the construction and sales branches, among others, determine the capacity of companies to determine the final consumer. In this way, large companies, due to the magnitude they represent, are external to the national market, while small and medium-sized companies have a more or less local scope, with the exception of one company for each group, who export part of their products to the market. Externally, these sales contribute very little to their total income.

It is also the case of companies that do not sell either inside or outside the local market. So, it is about companies that obtain their income from other sources, their field therefore are the communal, social and personal services. In the following graphs it can be observed how the sales in the national market and the sales abroad (exports) as well as other sources of income, contribute to the total income of the companies. 


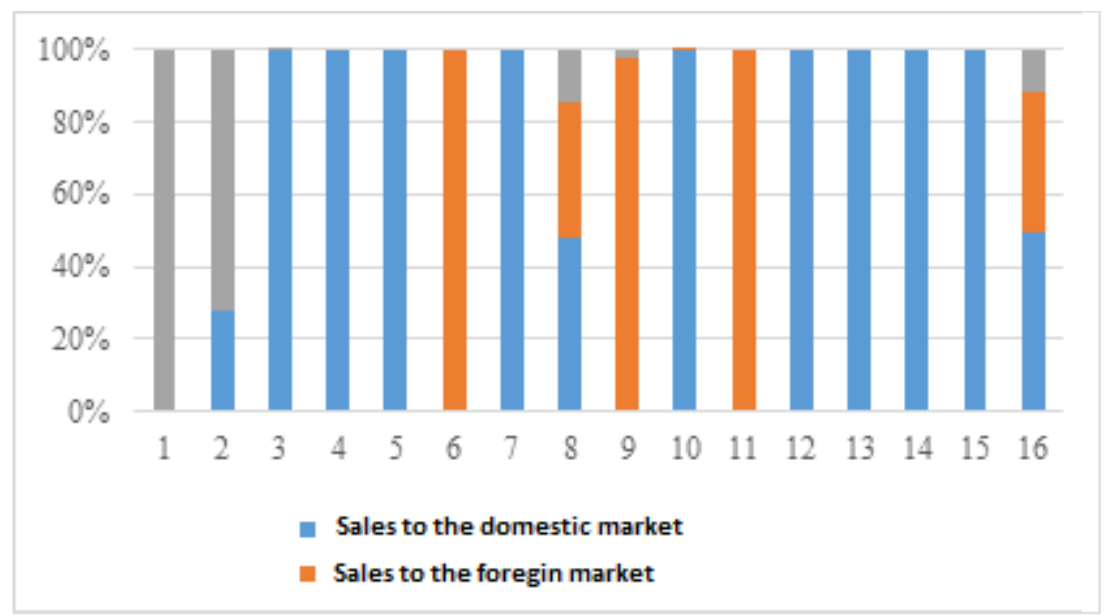

Figure 6. Structure of the income of large companies.

Source: Own elaboration with data from the ENTIC, 2013.

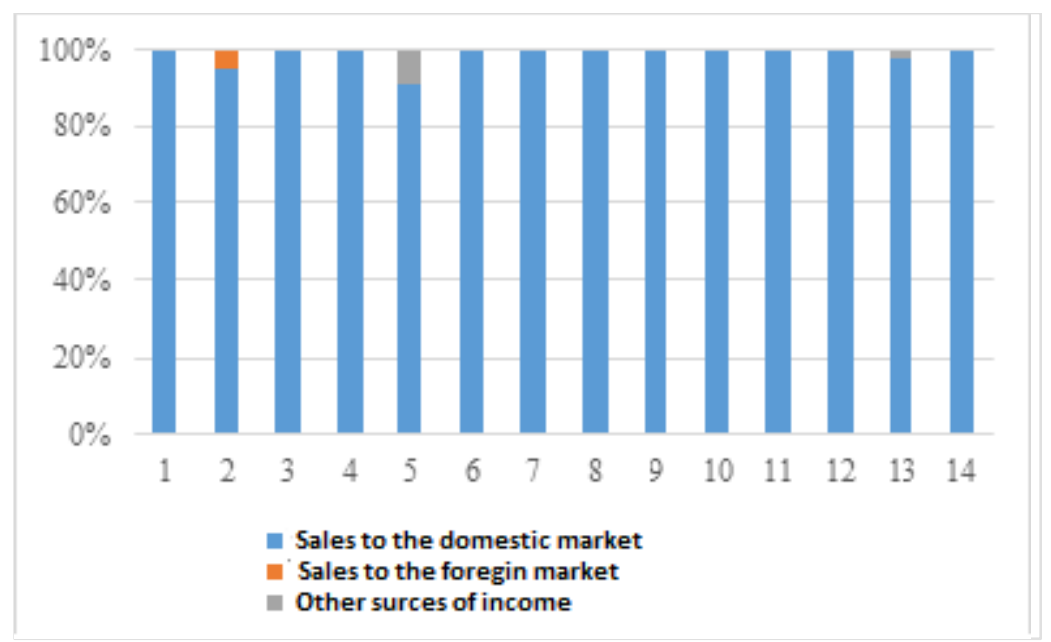

Figure 7. Structure of the incomes of medium-sized companies.

Source: Own elaboration with data from the ENTIC, 2013

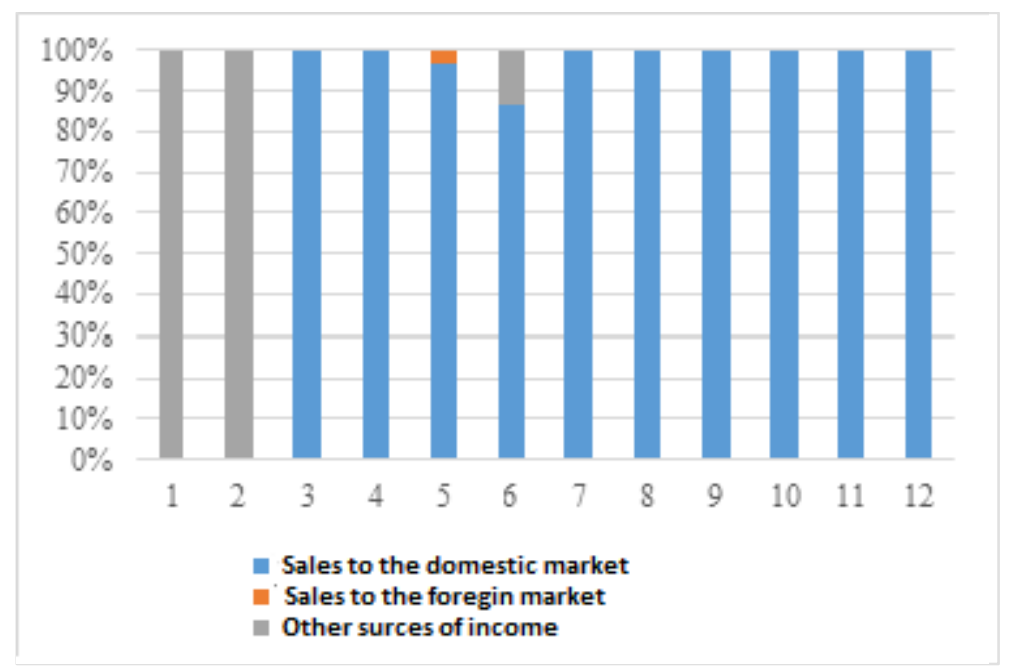

Figure 8. Structure of the income of small businesses.

Source: Own elaboration with data from the ENTIC, 2013 
When classifying the companies in these 3 groups according to the size as mentioned above, it is a function of the total number of personnel employed. It is analyzed the disposition of the means of communication. It can be seen that the results are similar between medium and large companies. The large companies to be hypothetically consolidated within the market, their technological equipment is also, a situation that shares with medium-sized companies. Companies classified as large achieve in this way $100 \%$ provision in fixed telephone lines and email and only $31.25 \%$ of the total of companies in social networks, percentage below the medians that report a $35.71 \%$ of the total of companies.

On the other hand, there is a considerable gap between small companies with these two groups (medium and large), although they share a low use of social networks and a high percentage in telephone lines. Being the group of small companies which represents $84.18 \%$ of the total population, according to the methodological document presented by INEGI for the ENTIC (2013) represents a central issue to guide policies for the use of ICTs by the bodies of competent governments. The following graph details the use of the media by companies in the classified groups:

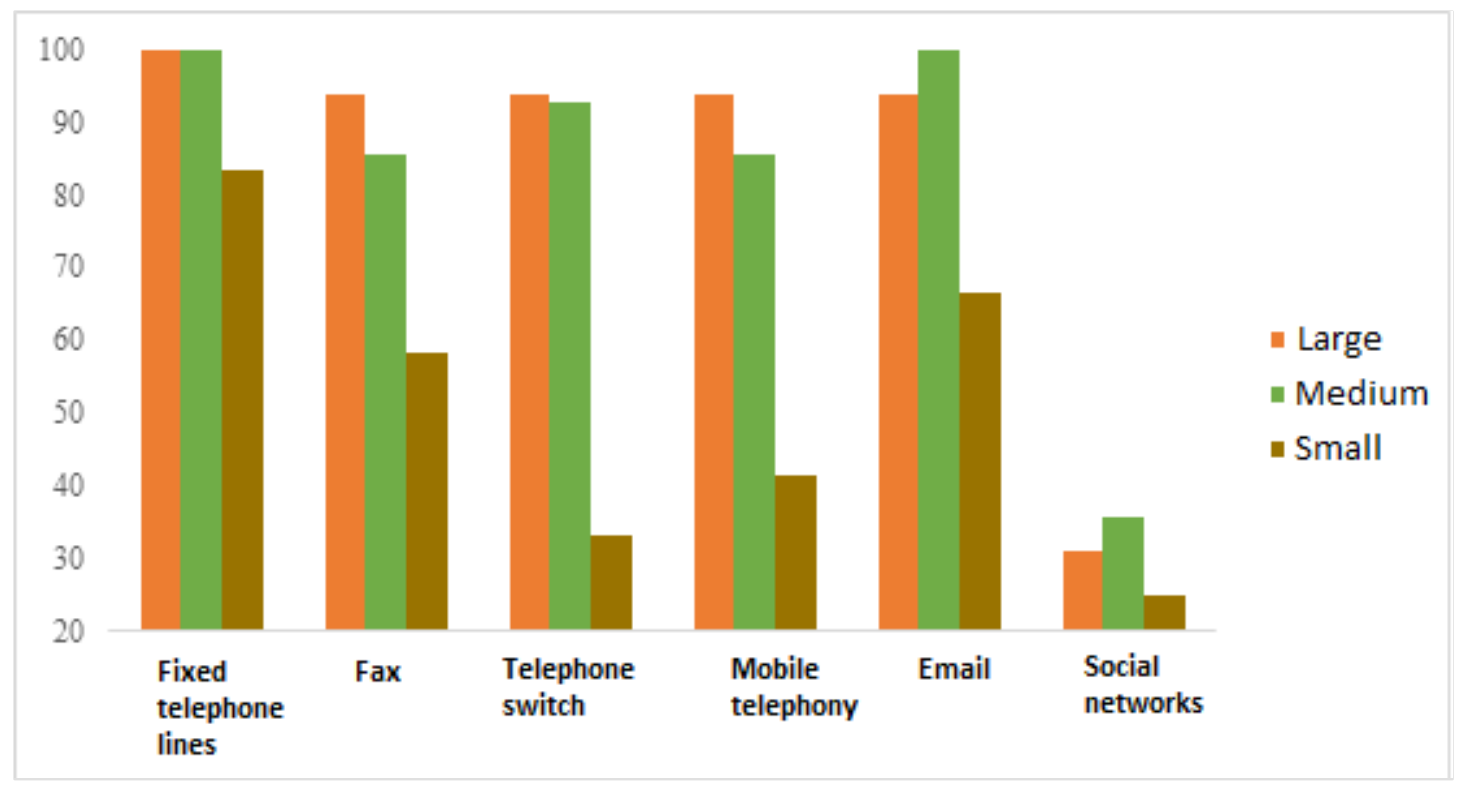

Figure 9. Disposition of the media by small, medium and large companies.

Source: Own elaboration with data from the ENTIC, 2013

Differentiating the size of the companies to perform the analysis allows to identify the technical and technological advantages of medium and large companies in terms of cutting edge and acquisition of computer equipment. In terms of equipment per worker, medium-sized companies have a .38 computer equipment greater than the average of the whole (.35). Large companies are in the middle and small businesses, as expected, are below the average half.

The high percentage of obsolescence of the computer equipment of small companies is evident, which results in a disadvantage when competing with medium and large companies. Because of this, small businesses have a market to gain and equipping can be a powerful measure to achieve this goal. We see this information summarized in the following table 7: 
Table 7. Obsolescence and per capita equipment of companies according to their size.

\begin{tabular}{|lllll|}
\hline Type of company & \multicolumn{5}{c|}{ Age of computer equipment \% } \\
& $\begin{array}{l}\text { Computer } \\
\text { equipment } \\
\text { per capita }\end{array}$ & Under 1 year & 1 to 2 years & $\begin{array}{l}\text { More than 2 } \\
\text { years }\end{array}$ \\
Large & 0.35 & 29.33 & 23.07 & 47.60 \\
Medium & 0.38 & 13 & 24 & 63 \\
Small & 0.31 & 6.5 & 4.3 & 89.2 \\
\hline
\end{tabular}

Source: Own elaboration

Regarding the use of ICTs to create competitive advantages within the market, it is found a more or less uniform behavior among the groups of companies. On the one hand, $50 \%$ of small businesses saw their sales favored with the use of the internet and $60 \%$ of these same companies increased their customer base. This speaks of a significant use of the internet. In the case of medium-sized companies, their time of processes and administrative activities was reduced with the significant use of the internet with $64.29 \%$ of the companies that declare using these ICTs for their operations.

With this indicator, it can be spoken at a first moment that medium-sized companies are more productive with respect to small and large companies. The results of the large companies are mainly due to the field of their activities highlighting manufacturing as predominant, in the medium-sized manufactures and services and small businesses services. It can be seen this in the following figure 10:

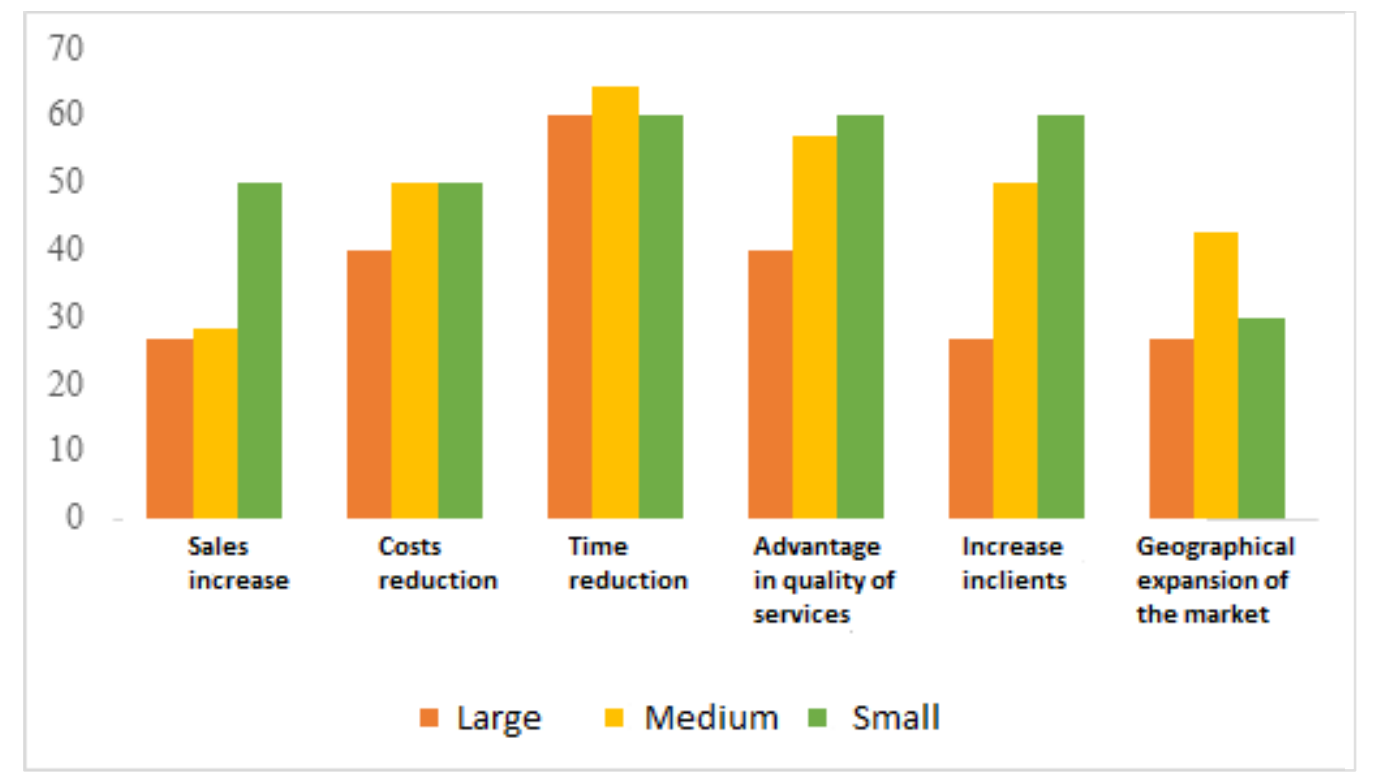

Figure 10. Competitive advantages of the internet for small, medium and large companies. Source: Own preparation with data from the ENTIC, 2013

The advantages provided by having an official website for each of the companies would represent an image positioning. The results presented for the web pages of the companies highlight the little use by small companies, having the biggest impacts for medium-sized companies, which is a more effective use to increase sales, offer quality services and a geographical expansion of the market. Large companies again fall short of the effects that 
medians could have, with web pages being a website where the characteristics are captured and the magnitude of these companies would expect these results. It can be seen this below:

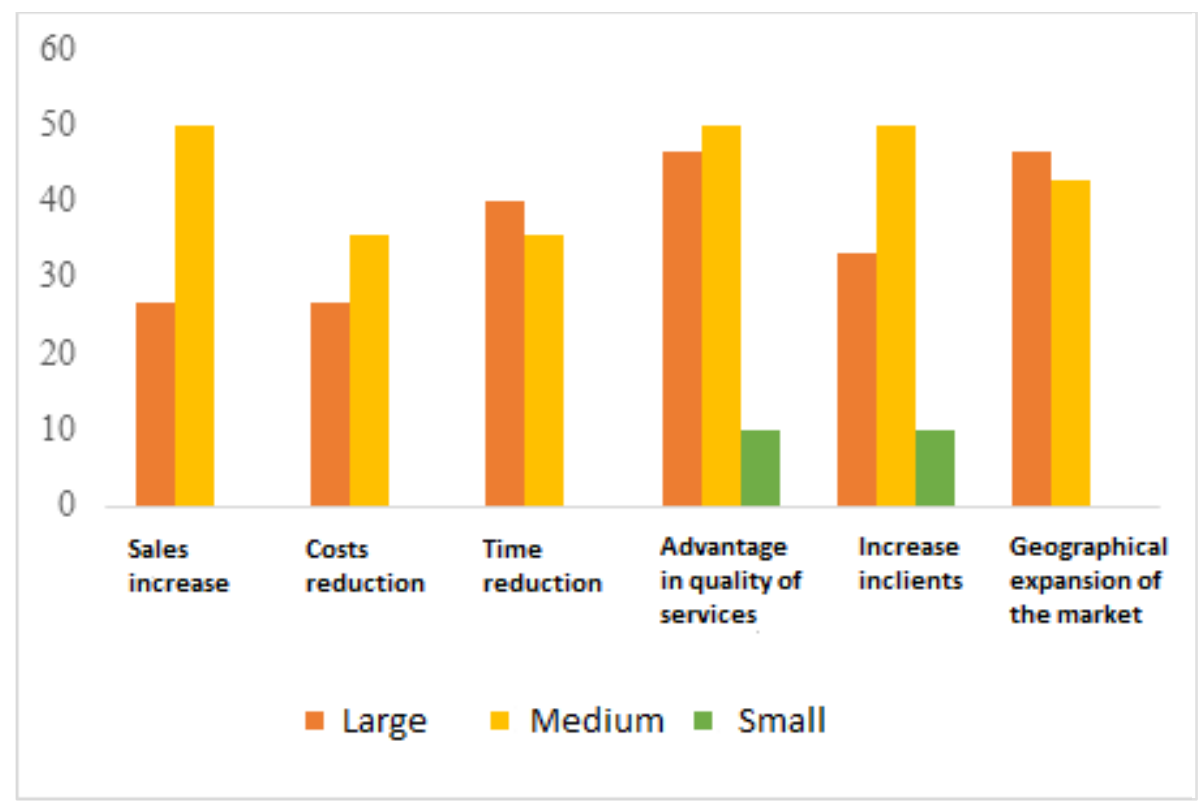

Figure 11. Competitive advantages of web pages by small, medium and large companies. Source: Own elaboration with data from the ENTIC, 2013

E-mail is another tool of ICT for the realization of the activities of companies and in view of its impact on promoting the skills seen in its prevalence for medium-sized companies in the points on the increase in sales, cost reduction, improvements in the quality of their products as well as increases in the client portfolio.

For medium-sized companies, it is a tool for brand expansion and positioning. The benefits that the medium companies declare in the ENTIC (2013) because they have emails with considerable percentages in these items show the importance of the adoption of this ICT.

On this point large companies were favored by the use of mail in a slightly longer time reduction on medium-sized companies with $73.33 \%$ over $71.43 \%$, while $40 \%$ of these same companies saw their market expanded geographically. In relation to small businesses, the percentages in terms of the impact of the use of electronic mail do not indicate a significantly beneficial trend, as shown below: 


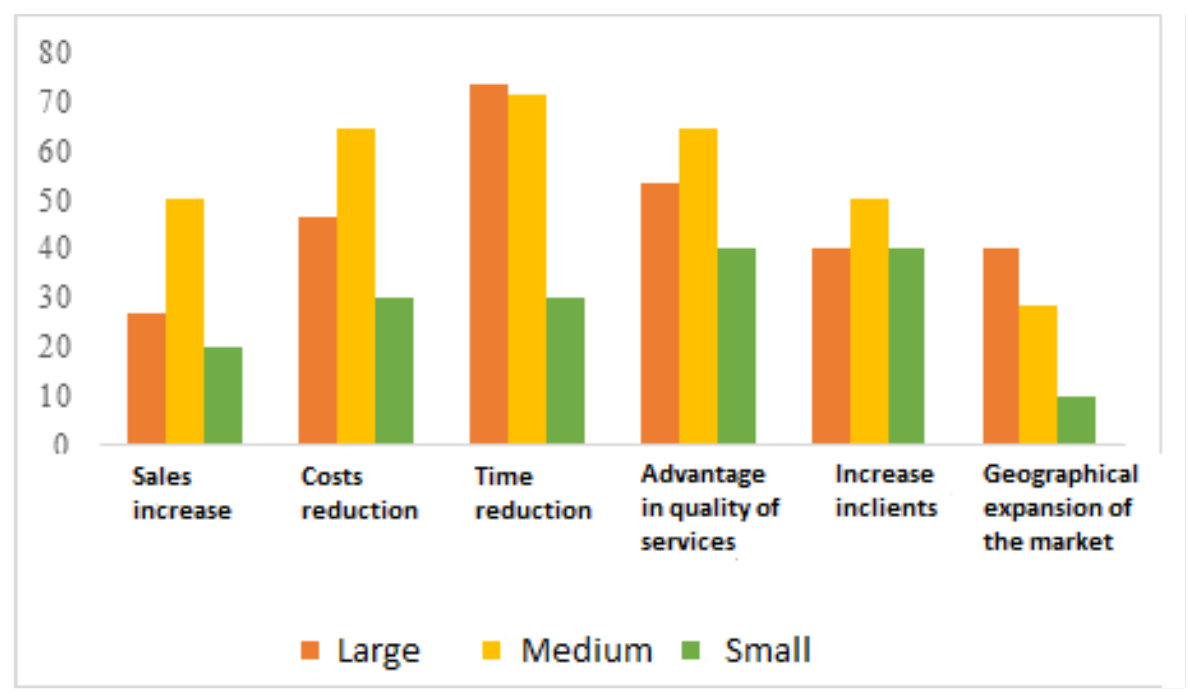

Figure 12. Competitive advantages of electronic mail by small, medium and large companies. Source: Own elaboration with data from the ENTIC, 2013

Finally, there are social networks as an ICT in which most of the companies have insignificant impacts as seen jointly and strengthen this thesis according to size. There seems to be a complementarity between large and small companies on the benefits of this ICT. The limited exploitation of ICTs by companies limits them to take advantage of benefits that would allow them to increase their sales through the positioning of their product, increase their customers and through these networks can be made known and achieve greater expansion of its national market and on a smaller state or regional scale.

Summarizing small companies are those who obtain advantages over social networks to increase their sales and increase the number of customers, although this tool is not the most remarkable of the analysis, this behavior can be reviewed in the following graph.

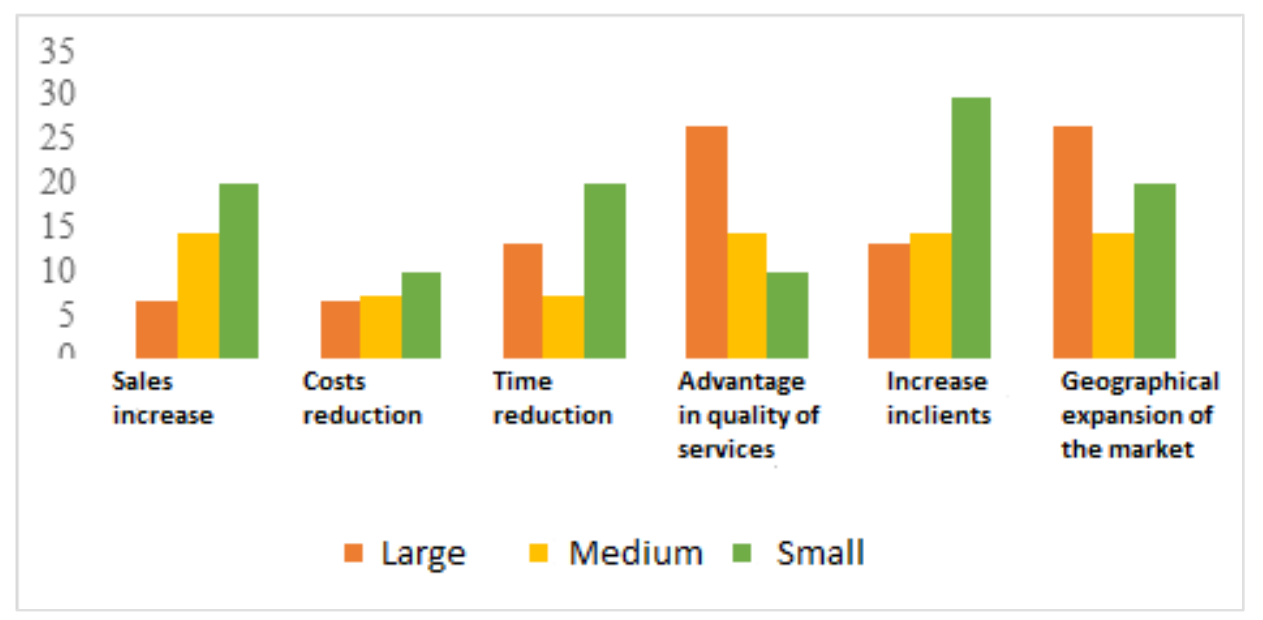

Figure 13. Competitive advantages of social networks by small, medium and large companies.

Own preparation with data from the ENTIC (2013).

In this general outline, it can be identified that the use of ICTs to create competitive advantages, according to the size of the companies, the medians are those that are favored most, followed by small and large companies. What can be said about the low level of updating and investment that large companies have to operate through the use of ICTs. 
Efforts in the adoption of ICT should be and is, as shown by this detailed analysis, by small and medium enterprises, since they are the entities that are obligated to invest in order to grow. In the case of large companies, the effort turns out to be less since they have reached a degree of maturity and consolidation within their market, they already have a client portfolio and their market is national and foreign.

The undoubted importance of technical and technological equipment for the disposition and use of ICTs by companies in any of its dimensions accompanied by users of these technologies: human capital converges in higher or lower revenues for companies.

For the analysis it is taken the total income of companies, presented previously and made up of sales to the domestic market, sales abroad and other types of income as an indicator of productivity that depends on the level of ICT equipment in this case is the investment in computer equipment and labor factor as the number of total personnel employed. The model to make the approximation to the productivity of the company would be represented by the following expression:

Average productivity model

$\ln P_{M E i}=\alpha+\beta \ln I_{T I C i}+\gamma \ln I_{\text {NOTICi }}+\delta T a m+\varepsilon_{i}$

Where:

$\alpha=$ intercept

$\ln P_{M E i}=\ln$ Productivity average per worker of the company $\mathrm{i}$

$\beta I_{T I C i}=$ ln Investment in ICT per company worker $\mathrm{i}$

$\gamma \operatorname{lnI}_{\text {NOTIC }}=\ln$ Investment in NOTIC equipment per company worker $\mathrm{i}$

$\delta T a m=$ Dummy of the size of the company

$\varepsilon \_\mathrm{i}=$ random error

Certain characteristics acquired by companies according to capital, personnel, type of activities they develop, size, administrative and production processes, among others, make them adopt working mechanisms, decision making about the distribution of functions, tools to be used. Thus, in the search for increasing returns, technical and technological tools are provided with which the times of the processes can be minimized and generally optimizing the company's human and material resources.

Through the general linear model of double logarithm to determine the average productivity of the workers through elasticities that show the increases that have the increase in $1 \%$ plus the ICT equipment or the non-ICT. The results of the model by stratum show a significance of $24.53 \%(\mathrm{R})$.

The constants by strata, 6.58 for the large ones, 5.83 for the medium ones and 5.25 for the small companies shows the level of equipment that each group has. These results are to be expected since large companies by size would have to have a fixed capital greater than medium and small companies.

In the coefficients of the general model, it is identified that the investment in ICTs increased by $1 \%$ through computer equipment, the average productivity per worker increases by $0.18 \%$, while by doing so in non-ICT investments (investment in furniture and equipment) the average productivity of workers grows by $0.25 \%$. These significant differences correspond to a low 
intensive use of ICTs by small Mexican companies that, as indicated before, represent $84.18 \%$ of the total population of the ENTIC, 2013.

By strata of companies, it is observed that for large companies the average productivity is $0.64 \%$ higher than the average productivity of small and medium enterprises. Being a linear regression statistical model it is referred to the characteristics of the data to validate the assumptions, so we find that the data come from a normal distribution.

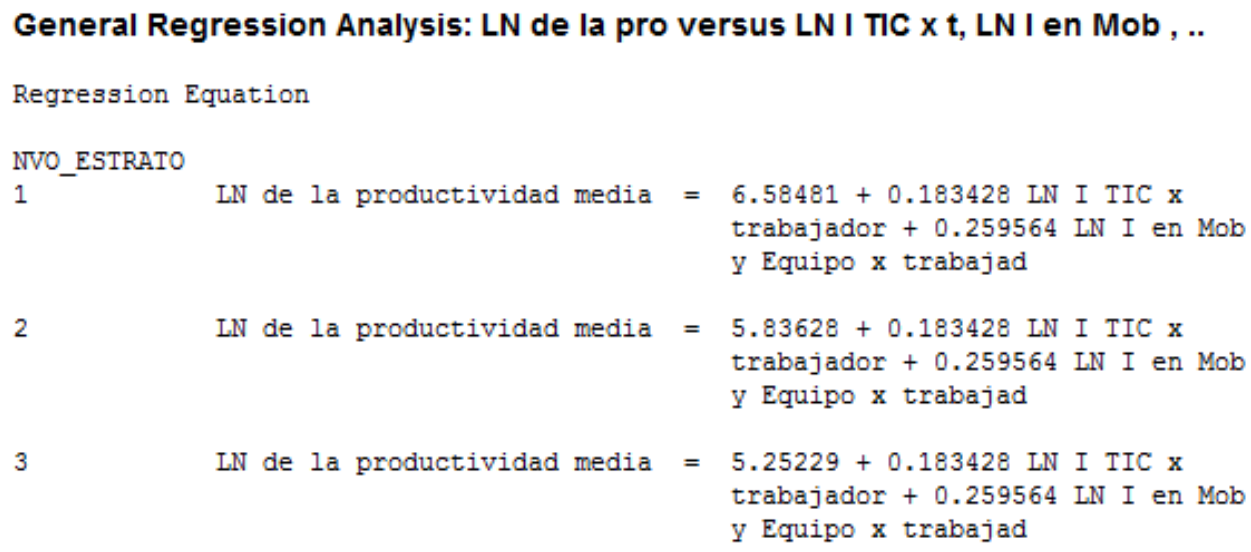

Figure 14. Results of the linear regression of the Average Productivity model

\section{Production model}

Starting from the function of production mostly used and exposed by Cobb and Douglas in 1948 , it is determined the relationship between the product with labor and the capital in which technology remains constant (Sánchez, 2016), in this way we will have:

$Q=A L^{\alpha} K^{\beta}$

Where:

$Q=$ Product

$L=$ Labor (Employed personnel)

$K=$ Stock of Capital

$\alpha=$ Work participation in the generation of added value or product

$\beta=$ Share of capital in the generation of added value or product

$A=$ Factor scale or efficiency parameter, which reflects the level of technology

Finally introducing the double logarithm, we will have:

$\ln I N_{i}=\ln A_{i}+\alpha \ln L_{i}+\beta \ln K_{i}$ 
Under this model scheme it is obtained the elasticities of the product of labor and capital. In this sense we take $Q$ as the total income of the company, A referring to a scale factor or parameter of technological efficiency and supported by the regression analysis where we calculate average productivity, where large companies are intensive in ICTs use, medium-sized companies to a lesser degree and finally to small ones such as those that make the best use of ICT. It will be used this same classification or parameters, where 1 uses the most technology, 2 uses medium technology and 3 uses less technology.

For $\mathrm{L}$ we will take the total of employed personnel and for $\mathrm{K}$ that represents the stock of capital, we take the total variable of investment in fixed assets 2012. In the first stage where we calculate the relations that have the product taken as the income of the companies of the sample with the explanatory variables, in this case of the total staff, the stock of capital and the level of technology, where stratum 1 is intensive companies, 2 medium-intensity companies and 3 those that use less technology, we have as a result that this model is adjusted by $76.9 \%$.

By increasing the 1\% employed personnel, the product increases by $1.10 \%$ as the most relevant variable, followed by stock of capital that increases by $0.78 \%$ in the same percentage. In the case of the strata that represent the intensity of the use of technology as a parameter, increasing one stratum to another results in a weight of $0.031 \%$, remembering that this is a classification variable, which is the result of moving from one stratum to another.

In the following figure, we can find the results of the regression, the normality graphs are presented to fulfill the assumptions of distribution of the data of the sample.

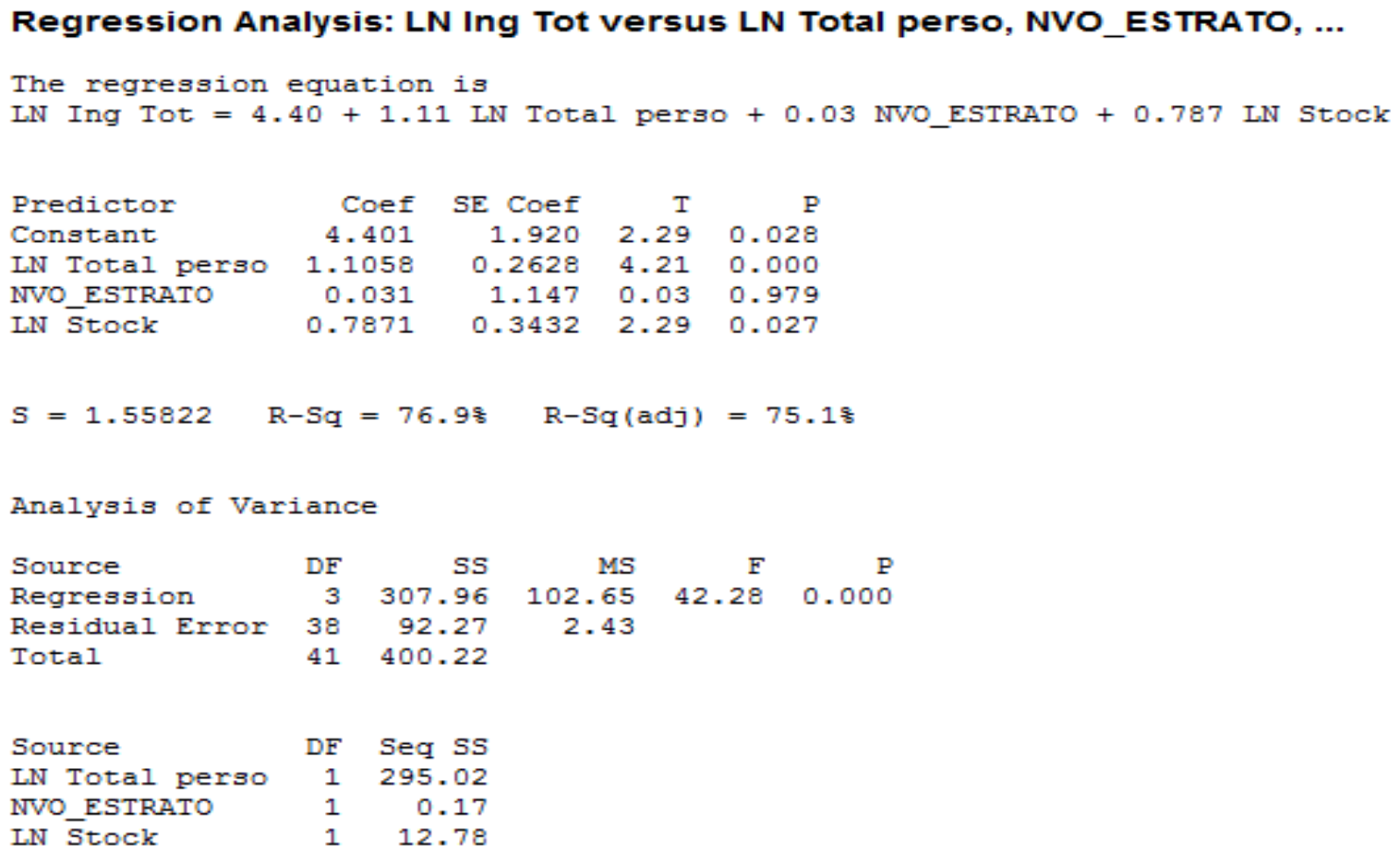

Figure 14. Results of the linear regression of the production model.

Source: Own elaboration 


\section{Conclusions and recommendations}

The delay that Mexican companies present in their technological equipment allows them to be placed at a disadvantage compared to multinational companies established in our country. The companies collected for this analysis place most of their sales in the national market, so it is of significant importance the decision making by the top managers to rethink investment efforts aimed at Information and Communication Technologies.

These results are preliminary and represent an exercise so it is recommended to conduct future studies thoroughly and with the entire sample. The efforts made by companies in their investments are based on the purchase of machinery and equipment $(30 \%)$, followed by computer equipment and peripherals $(26 \%)$, which means the importance in the operation of the companies the use of TIC's.

The companies studied continue to use traditional means of communication such as fixed telephone lines, fax and commutator. On the other hand, by making use of e-mail and the Internet, companies benefited from reducing their costs, increasing the quality of their services and increasing their client base.

In the results of the regression model in the coefficients identified that the increase in $1 \%$ investment in TIC's through computer equipment average productivity per worker increases by $0.18 \%$, while doing so in non-ICT investments (investment in furniture and equipment) the average productivity of workers grows by $0.25 \%$.

It should also be noted that by increasing the $1 \%$ employed personnel, the product increases by $1.10 \%$ as the most relevant variable, followed by stock of capital that increases by $0.78 \%$ in the same percentage, in the case of the strata that represent the intensity of the use of technology as a parameter, increasing one stratum to another results in a weight of $0.031 \%$, remembering that this is a classification variable, which is the result of moving from one stratum to another.

The positioning of the companies in the Mexican market does not turn out to be simultaneous, but it raises a series of actions that guide the companies in the growth and permanence, within the actions that these companies carry out, the product of the realization of this research is a low investment with less than $\$ 999.00$.

The companies under study, mainly national capital (78\%) have to increase the training of their staff to make use of ICTs, programs such as PROSOFT 3.0 created to promote innovation and for the adoption and development of new ICT's must be exploited since $93 \%$ of companies do not receive support of this type.

Another point that should be noted is the necessary update of the computer equipment used by companies, since $63.67 \%$ of companies have equipment greater than two years old and taking into account depreciation per year $(30 \%)$ is relevant to take measures for replacement.

The medium and large companies to have consolidated their market their efforts do not have to be comparable to those that have to do small businesses, so it is necessary to formulate strategies through subsidy ways of taxes, strengthening of government programs for the small business, so that this gap is shortened. This obsolescence in small businesses represents a significant obstacle since they have a market to win.

It is important to mention that the low equipment in computer equipment (.35 per capita of the total of the companies) responds to a circumstance of disadvantage. The employed personnel are limited to the development of their activities through these technologies that would allow them to limit their efforts and minimize times and costs. 
Finally, electronic commerce should be encouraged among companies, since this way marks the future of a new virtual generation that is friendly to the environment, which would allow cost reduction and meet human needs simultaneously.

\section{References}

Cantú, S. O. (2006). ¿Qué es la gestión de la innovación y la tecnología (GInnT)?, Journal of Technology Management \& Innovation, vol. 1, núm. 2, june, 2006, pp. 64-82

El Economista. (17 de Diciembre de 2015). Precios de Petróleo son de alto riesgo: Goldman Sachs. El Economista.

Figueroa, G. M. (2015). El proceso de gestión de Innovación Tecnológica: sus etapas e indicadores relacionados, Revista Venezolana de Análisis de Coyuntura, vol. XXI, núm. 1, enero-junio, 2015, pp. 59-90.

Hernández, L. M. (2009). Una revisión de la interpretación económica sobre la innovación., Journal of Technology Management \& Innovation, vol. 4, núm. 4, 2009, pp. 139-149.

Luter, R. R. (1998). Desarrollo regional e innovación y desarrollo tecnológico Investigación y vinculación tecnológica: un enfoque regional pp.139-162. Culiacán Rosales, Sinaloa: BUAP, UAS.

OCDE. (2013). Indicadores de Ciencia, Tecnología e Industria de la OCDE 2013. México: OCDE.

RAE. (11 de 01 de 2016). RAE. Recuperado el 11 de 01 de 2016, dehttp://lema.rae.es/drae/srv/search?id=wCP3BIIJRDXX2uYFygrz

Sánchez, A. M. (1 de Mayo de 2016). Universidad del Cauca. Obtenido de http://www.unicauca.edu.co/porik_an/imagenes_3noanteriores/No.9porikan/porikan_7. pdf 